\title{
DESIGN DE SERVIÇOS E O RELATIONAL WELFARE: uma reflexão sobre transformação do projeto e entrega de serviços públicos a partir do caso de uma empresa social
}

Maria Clara LIPPI*

\begin{abstract}
*Mestre e bacharel em Engenharia de Produção, professora substituta da Universidade Federal do Rio de Janeiro, mariaclara.lippi@gmail.com
\end{abstract}

Recebido em: 06/07/2016 - Aprovado em: 21/03/2017 - Disponibilizado em: 01/07/2017

\begin{abstract}
RESUMO:
As reformas dos serviços públicos pautadas pelo New Public Mangement (NPM) surgiram para mitigar crises econômicas e sociais, instituindo novos métodos direcionados ao projeto e ao aumento da entrega de serviços focados no cliente, que implicariam em maior valorização do dinheiro público. Esta mentalidade de prestação de serviços, focada em resultados e no cliente e que sustenta as abordagens vigentes sobre os serviços públicos, encontra dificuldades emincorporar aspectos relacionais e colaborativos entre as pessoas, expondo os limites do estado de bemestar atual. Surge, portanto, o conceito de Relational Welfare apresentado por este artigo e aprofundado no estudo particular de uma organização com fins sociais e de seus projetos. As principais conclusõesda pesquisa residem em análise de seus resultados sob a ótica do design de serviços.Nesse sentido, observa-se tendências contrárias à lógica tradicional de que os proprietários dos meios de produção decidem o que produzir.Opta-se por intervenções sustentáveis e colaborativas que desafiam as perspectivas tecnocrática e burocrática, dando vida a novos modelos de produção. As principais características de tais modelos consistem na democratização dos meios de invenção e produção, e na redução da distância entre inventor e empreendedor. Estes movimentos e modelos devem ser incorporados às discussões políticas e no projeto de serviços públicos.
\end{abstract}

Palavras-chave: design de serviços; serviços públicos; projeto; gestão pública; inovação social

\begin{abstract}
:
New Public Management (NPM) guided public services'reform in order to mitigate economic and social crises, and established new methods to design and delivery services focused on the client. This service design approachhas substantial limitation on incorporating relational and collaborative aspects between people. Therefore, current welfare state is challenged. This article presents the concept of Relational Welfareand analyses a case study proceeded in an organization with social purposes. The main conclusions of the research are made by the perspective of servicedesign. The author observed trends inchoosing sustainable and collaborative interventions that challenge the technocratic and bureaucratic perspectives, giving life to new production models. The main features of these models consist in the democratization of the means of invention and production. Also is expected the distance between inventor and entrepreneur get shorter. Such movements and models must be implemented into public policy and service's design.

Keywords: service design; public services; public management; social innovation
\end{abstract}

\section{Introdução}

DI PIETRO (2014), define serviço público como toda atividade que a lei atribui ao Estado para que a exerça diretamente ou por meio de delegações, com o objetivo de satisfazer concretamente às necessidades coletivas, sob regime total ou parcialmente público.
O desempenho das ações governamentais comumente é utilizado como argumento em debates sobre tamanho e atuação do Estado. Há, de um lado, defensores do Estado mínimo e seus argumentos utilizam análises sobre a ineficiência estatal para se sobreporem. Por outro lado, existem os que defendem a atuação do Estado como a única possibilidade 
de produzir resultados em certas áreas nas quais as falhas de mercado se apresentam como crônicas, segundo BRESSER PEREIRA (1998), recusando assim o pressuposto neoliberal da ineficiência intrínseca e generalizada do Estado.

Atualmente, a sociedade se depara com questões que emergiram após o estabelecimento do WelfareState, na década de 50, como envelhecimento da população, mudança nas estruturas familiares, alterações climáticas, e aumento da desigualdade social (MURRAY et al., 2010).

A resposta dos governos tende a estar/estiveram voltada à reforma dos serviços públicos. Nesse contexto, a New Public Management (NPM), por exemplo, norteou a reforma e governança dos serviços públicos, com ênfase a melhoria do desempenho do Estado, como resposta à decadência da administração pública tradicional. Dessa forma, as pressões de mercado foram levadas ao setor público por meio de privatizações e incentivo à competição, de modo que as técnicas de gestão do setor privado também foram absorvidas pela administração pública. Ou seja, estabeleceram-se metas e objetivos para serviços e gestores, cujo desempenho seria mensurado e controlado, além do aumento de injeção de recursos para serviços públicos, com foco na personalização como meio para proporcionar serviços orientados aos usuários (DUNLEAVY; HOOD, 1994).
Segundo MULGAN (2012), mesmo que haja evidências de que os padrões de serviços públicos melhoraram, não existe uma relação de que isto tenha sido acompanhado pelo aumento dos níveis de confiança pública. Em seu trabalho, COOKE; MUIR (2012) salienta que as reformas da NPM surgem para mitigar crises econômicas e sociais, instituindo novos métodos direcionados ao projeto e ao aumento da entrega de serviços focados no cliente, que implicariam em maior valorização do dinheiro público. No entanto, o autor critica tal abordagem:"O foco na entrega de resultados mensuráveis tem negligenciado a importância das relações humanas. Ele corre o risco de reduzir a complexidade e textura da experiência humana a um simples número, levando a políticas e serviços que não abordam o cerne de um problema." (COOKE; MUIR, 2012, p. $6)$.

Desta forma, o foco em resultados minimiza o papel das relações na melhoria da vida das pessoas. Além disso, a escolha deste modelo "puro" implica em um grupo restrito de pessoas atribuir o que deve ser considerado desempenho, resultado e valor que estarão a serviço dos demais. MULGAN (2012) preconiza que as relações humanas devem ser o centro do pensar a respeito do governo e, particularmente, das operações dos serviços públicos.

A mentalidade de prestação de serviços, que sustenta o pensamento sobre os 
serviços públicos, encontra dificuldades para pensar sobre as relações entre as pessoas, ao contrário do que ocorre quando do foco no usuário. Este é um desafio de reforma social, expondo tanto os limites do estado de bemestar atual e muitos dos modelos de reforma vigentes. Em consonância, COTTAM (2011) diz que "o Estado do bem-estar social é baseado em um modelo ultrapassado e transacional, e precisa ser substituído por algo que seja compartilhado, coletivo e relacional".

Este artigo busca apresentar o conceito de bem-estar relacional (RelationalWelfare) e explorar possibilidades de sua articulação com o design de serviços, principalmente daqueles relacionais. Para tal, foram construídos dois arcabouços conceituais que apoiaram o desenvolver do objetivo deste trabalho: serviços relacionais e RelationalWelfare. O primeiro foi baseado nas discussões e referências que emergiram da disciplina Design de serviços. O segundo, por sua vez, decorre de buscas realizadas na internet e em bases.

Nesta atividade de busca, observou-se poucas, ou quase nenhuma, publicações acadêmicas sobre o assunto, donde se destaca Hilary COTTAM - designer britânica - e suas atividades para fomento do RelationalWelfarena instituição chamada Participle (www.participle.net). Inclusive, aparentemente, a autora cunhou o termo, o qual está associado ao "estado relacional" e à“economia solidária”. No entanto, apesar de respectivos conteúdos incorporados ao arcabouço conceitual quando considerado pertinente, estes termos não são o foco deste trabalho.

Em decorrência dos resultados de busca, a autora considerou relevante explorar a atuação da organização conduzida por COTTAM, como um estudo de caso, baseado em análise documental. Para tal, foram coletadas informações disponibilizadas pelo site da instituição, além de matérias e publicações diversas.Por fim, no tópico da conclusão, há a tentativa de analisar o que foi estudado sob a ótica do design de serviços.

\section{Referencial teórico}

Este tópico apresenta o desenvolvimento dos principais conceitos trabalhados pelo presente artigo.

\subsection{Serviços relacionais}

CIPOLLA (2008) divide serviços em dois grupos: os padronizados e os que emergem como solução de comunidades criativas. Os serviços padronizados possuem dois atores, que desempenham papéis diferentes, onde um serve o outro, em interações lineares. Em contrapartida, as soluções de serviço das comunidades criativas - os serviços colaborativos - não são prescritíveis, dado que são baseadas em abordagens de cooperação, cujos benefícios são gerados e partilhados pelos participantes.

Em consonância, MANZINI (2009) afirma que os serviços colaborativos são 
fortemente baseados em interações interpessoais, geralmente não lineares, as quais demandam envolvimento direto e ativo de todos os atores interessados e,portanto, confiança e qualidades relacionais. Estas características, "por definição, não podem ser impostas" (MANZINI, 2009, p. 4) e, eventualmente, projetadas e prescritas. Tais soluções tendem a surgir casuisticamente, mas operações estratégicas no design podem transformar estar iniciativas discretas e serviços confiáveis (JÉGOU; MANZINI, 2008).

Dentro do universo dos serviços colaborativos, este trabalho busca dar ênfase aos chamados serviços relacionais, definidos por CIPOLLA (2012) da seguinte forma:"Serviços relacionais são um tipo particular de serviço colaborativo, no qual os participantes não necessitam apenas ser operacionalmente ativos e colaborativo, mas também bem-dispostos e com vontade de se relacionarem com outros de forma pessoal. " (CIPOLLA, 2012)

Os serviços relacionais pressupõem interação presencial e pessoal entre os indivíduos, como meio para gerar benefícios reais e comuns. A dinâmica relacional é essencial para a operação do serviço, uma vez que compõe seu resultado e benefícios produzidos pelo mesmo. Assim, a confiança, responsabilidade mútua e intimidade são qualidades relacionais que movem estas soluções. Sua proposta consiste, a partir dos encontros interpessoais, em gerar bem-estar e modos e viver baseados no compartilhamento e na colaboração (CIPOLLA, 2009)

\subsection{Relational Welfare}

Atualmente, há uma incompatibilidade entre os serviços oferecidos e as necessidades da população. O conceito de Relational Welfare surge mediante o propósito de ser um meio para provimento de serviços que suporte as necessidades da população. COTTAM (2011) sustenta este argumento a partir de três motivos.

O primeiro deles consiste na premissa de que a natureza dos problemas que o Estado de bem-estar social se propõe a tratar mudaram. Fenômenos como envelhecimento da população, surgimento de doenças crônicas, etc. não existiam quando o Estado de bem-estar social foi projetado.

$\mathrm{O}$ segundo aspecto se apoia na tecnologia. Os serviços relacionais são geralmente locais. Logo, se faz necessário que relacionamentos sejam construídos e que, por conseguinte, conhecimentos sejam compartilhados. As plataformas tecnológicas viabilizam este cenário.

Por fim, as abordagens voltadas a reforma falharam por não conciliar economia a melhoria de resultados. Além disso, as restrições gerenciais e burocráticas do Estado dificultam articulações sistêmicas e delimitação de fronteiras entre economia e bem-estar. 
Dessa forma, COTTAM (2011) defende que modelos relacionais de bem-estar devem surgir propiciando mais condições sociais e de colaboração. Segundo a autora, esses modelos tendem a emergir das margens da nova economia social. As principais características destas novas abordagens são direcionadas a cuidados, educação, bem-- estar, alimentação e energia, a partir do uso intensivo de sistemas distribuídos. Por tanto, as fronteiras entre produção e consumo tornam--- se difíceis de serem definidas; há ênfase na colaboração, e um papel forte para valores pessoais e missões.

A autora propõe cinco princípios para definir e sustentar o bem-estar relacional, a saber:cuidar de causas primárias; adotar abordagem voltada ao desenvolvimento; focar nas relações e não em infraestrutura; semear e patrocinar modelos alternativos; e facilitar o diálogo.

A organização em que atua, a Participle, tem desenvolvido novas abordagens para o estado de bem-estar, partindo de problemas sociais arraigados em direção ao desenvolvimento de novas soluções que podem ser escaladas nacionalmente.

O primeiro princípio, o qual diz respeito à atenção às causas primárias, está centrado na necessidade de analisar as fronteiras entre a economia e o bem-estar, com vistas, principalmente, à redução das desigualdades sociais. Ou seja, o estado de bem-estar social só é sustentável se houver uma estratégia econômica capaz de atender a estas causas básicas.

Nosso sistema de bem-estar existente não é construído em torno de oportunidades de desenvolvimento para a mudança. O estado de bem-estar tem de começar com uma visão de alto nível de como se gostaria de viver. Tal visão seria realizada na prática, com ferramentas e sistemas concebidos para apoiar abordagens de desenvolvimento, apoiadas por medidas que reforçariam o desenvolvimento, relações e partilha de recursos coletivos. As metas de serviço atuais são geralmente econômicas, pois eles suportam um objetivo do mercado global de crescimento econômico e os fatores humanos são deixados de lado. Portanto, se fazem necessárias medidas de mudança social que conduzam às formas adequadas de investimento.

Historicamente os nossos modelos de bem-estar são baseados em infraestrutura centralizada: recursos e modelos de serviços são projetados a partir da perspectiva dessas instituições. Um estado de bem-estar futuro, terá de relegar para segundo plano esta infraestrutura tradicional, a cultura, os sistemase as políticas que giram em torno dele. Os recursos que devem ser direcionados aos novos modelos, os quais são bastante fortes termos de relacionamento e contato social, e são distribuídos pelas possibilidades da tecnologia moderna.

Dessa forma, é preciso investir em novos modelos e sistemas distribuídos que 
sejam aptas a apoiar e galvanizar a capacidade coletiva e as soluções compartilhadas. A falta de compreensão da relação dinâmica entre o Estado e o cidadão é uma das fraquezas fundamentais do modelo Big Society. Na redefinição da relação entre a economia e o Estado social, se faz necessário repensar a alocação de recursos para pesquisa e desenvolvimento de forma sistemática. $\mathrm{O}$ apoio do Estado para fomentar estas soluções é fundamental.

A política tem de criar as condições para um estado de bem--- estar relacional, para novas formas de criatividade, para desenvolvimento de conversas e diálogos. É através desta nova conversa que algo compartilhado, coletivo e relacional serácultivado. O bem-estar relacional é uma abordagem que promove o capital social, definido em princípio e prática, pelas possibilidade e relações humanas.

Modelos de bem-estar relacionais são abertos a todos (como os problemas que abordam) em contraste direto com os modelos antigos. Quanto mais se faz uso de serviços relacionais, mais fortes são estes modelos. A abordagem relacional define não apenas os objetivos, mas a forma como atingi-los. Os relacionamentos são a base para que seja possível construir serviços públicos que promovam boas relações.

O Estado precisa apoiar ativamente, semear e fornecer modelos de trabalho de diferentes formas de organização, valorizando e proporcionando alternativas à esfera doméstica e para o mercado. Bem-estar relacional oferece um estado definido, em princípio e na prática, pela colaboração e por relacionamentos, em vez da agenda de reforma institucional e eficiência.

\section{O caso Participle}

Hilary COTTAM fundou Participle em 2007, onde surgiu uma metodologia participativa para desenvolvimento de modelos novos e sustentáveis aptos a operar na concepção atual de bem-estar. $\mathrm{O}$ modelo atual apresenta manifestações de ruptura entre o Estado e o cidadão. Para COTTAM (2011), "o bem-estar relacional não se trata apenas de teoria, na Participle foram criados exemplos de como ele pode realmente operar".

O trabalho da Participle inicia-se com as pessoas e suas comunidades, colocando o indivíduo no centro, em vez de o Estado. Membros da equipe conviveram junto a famílias porque há o interesse em aprender com os locais onde a necessidade é maior, e onde o Estado de bem-estar em sua forma atual parece mais desafiado. Dessa forma, a organização acredita que se é possível projetar soluções que gerem benefícios aos mais necessitados, é provável que estas sejam replicáveis para muitos.

No site da organização, há a seguinte descrição de sua missão:"Participleé uma empresa social sediada em Londres, operando por todo Reino Unido. Nós projetamos, 
desenvolvemos e dimensionamos soluções inovadoras para os desafios sociais contemporâneos. Nosso objetivo é transformar a forma pela qual os serviços públicos são projetados e entregues. " (www.participle.net/about/our approach/, tradução livre)

Os critérios empregados para instalação de iniciativas são voltados ao fato de que a maioria dos serviços públicos não permite que os cidadãos alcancem seu potencial e, como resultado, passa a existir um gap muito grande entre as expectativas dos cidadãos e a forma pela qual eles são prestados. Outras soluções foram implantadas ao longo da história como, por exemplo, as privatizações. No entanto, sabe--- se que os esforços para alcançar a eficiência ou inovação através delas são amplamente reconhecidos por não ter alcançado o resultado desejado.

Nesse sentido, a Figura 1 elenca e descreve sinteticamente os principaisserviços projetados pela Participle.
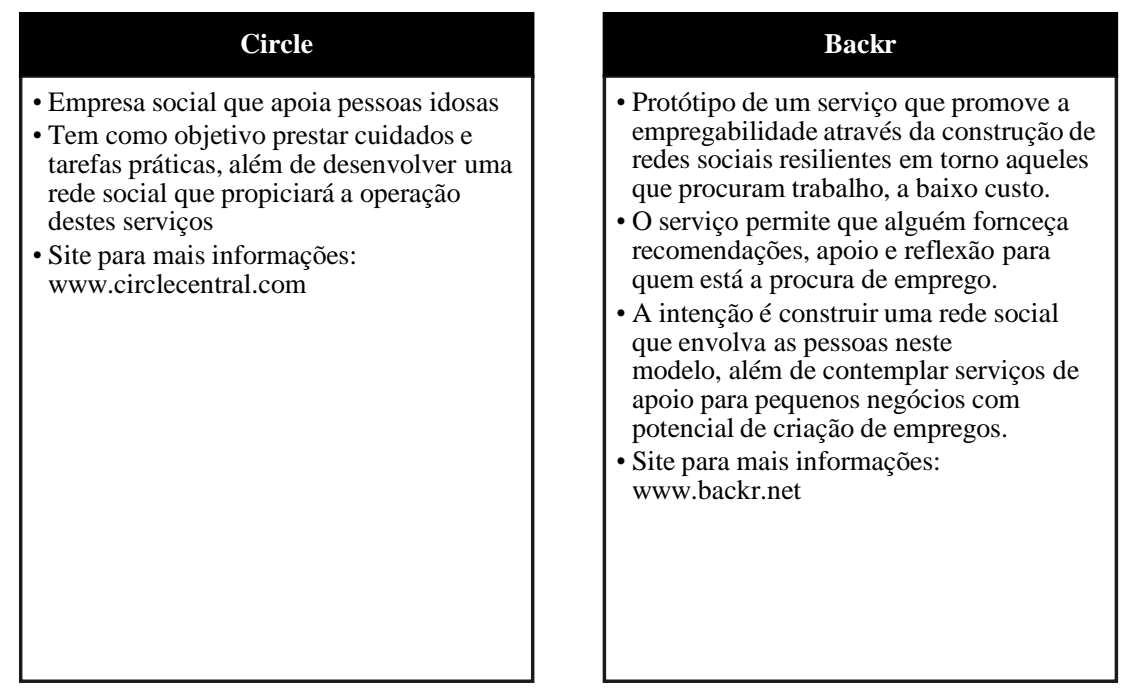

\begin{tabular}{|l|}
\hline \multicolumn{1}{|c|}{ Life } \\
\hline - Experiência de empoderamento para \\
famílias que encaram muitas dificuldades \\
no dia a dia \\
- As famílias possuem potencial e \\
capacitações próprias para mudar suas \\
proprias vidas, criando relações que \\
propiciem diálogos desenvolvedores. \\
- O programa fornecede um framework \\
para apoiar esta transformação, além do \\
convívio durante o processo. \\
- Outro diferencial é a mudança do papel \\
dos serviços sociais \\
tradicionais/transacionais, que deixam de \\
ser meros preenchedores de formulários \\
para de fato estabelecerem relações que \\
promoverão reais mudanças naquela \\
família. \\
- Site para mais informações: \\
www.alifewewant.com \\
\hline
\end{tabular}

Figura 1 - Principais serviços desenvolvidos pela Participle Fonte: A autora, a partir de informação dos sites indicados

A abordagem adotada pela Participle para desenvolver novos serviços públicos é guiada por quatro princípios, a saber:

- Colaboração: os trabalhos funcionam com grande proximidade aos parceiros, que fornecem conhecimento e financiamento. Para tal, foram desenvolvidos processos de comunicação e workshops, que buscam angariar envolvimento diverso dos indivíduos. É considerado um princípio que garante sucesso a projetos no setor privado, de públicos central e local.

- Condução pelo usuário: apesar dos processos de design serem"conduzidos" pelos usuários, ele conciliar staff da linha de frente e especialistas no âmbito do projeto do serviço. Cabe destacar que o objetivo 
da organização não é ter ideias por si só. A intenção é construir soluções a partir ideias que surgem dos diversos envolvidos, de modo que sejam viáveis quanto sua implantação.

- Alta iteratividade: foco na prototipagem rápida das ideias, queenvolve o desenvolvimento de serviço para testes e melhorias em ciclos rápidos. A Participle se inspira no Lean Startup neste aspecto.

- Foco no resultado final: utilização de técnicas de design centradono usuário para projetar serviços que serão demandados e terão alto grau de usabilidade. Uma vez concebidos, há foco criação de protótipos, testes beta e lançamento dos serviços. O objetivo é criar serviços viáveis de ser implantados pelos parceiros ou de forma independente.

\section{Conclusão}

O nosso estado de bem-estar existente e serviços públicos operam com base em princípios altamente centralizados. $\mathrm{O}$ debate atual sobre a devolução de mais poder para as instituições locais não alcança o cerne da questão, uma vez que muitas questões são tratadas para e por pessoas e comunidades.

Sob uma lógicabottom-up, as abordagens participativas são dependentes e sustentadas por um modelo mais distribuído. Eles não apenas servem as pessoas, mas criam capacidades em si mesmas, como forma de apoio a iniciativas. Daí, surge um processo iterativo de quanto mais é usado, mais sustentável torna--- se como experiência, e os recursos são distribuídos entre os membros.

Tais soluções distribuídas mudam radicalmente a natureza da relação entre o indivíduo e o Estado. A nível local, a interação é mais "humana" e pessoal, a colaboração é mais viável e uma verdadeira conversa em torno de questões de prioridades e contribuições se torna possível, reforçando ainda mais as relações. Finalmente, é importante notar que estas instituições distribuídas não foco nas relações e não na infraestrutura.

O Mercado se coloca hoje como grande regente das decisões e conflitos que definem o consumo e a produção contemporâneos, interferindo na formação e modelagem de uma sociedade individualista, alheia aos impactos econômicos e ambientais colaterais ao modus operandi vigente na vida cotidiana.

Os efeitos negativos que o Mercado provoca são negligenciados muitas vezes (notadamente pelos economistas), para evitar sua inclusão nos custos e na consequente formação de preços camuflados. De um lado, o impacto ambiental oriundo da insustentável capacidade de vazão de todos os eflúvios da produção e do consumo, e o esgotamento dos recursos essenciais; e, do outro, o aumento das desigualdades e o empobrecimento das relações sociais. 
Conforme observou Marx, o poder pertencia a quem controlava os meios de produção, em razão da expertise e dos equipamentos e custos de produção em larga escala. Os proprietários dos meios de produção decidem o que produzir. Porém, este fenômeno não é um imperativo. Existem indícios ou manifestações (quase sempre locais) que jogam contra esta tendência geral. São movimentos que optam por intervenções sustentáveis e colaborativas que desafiam as perspectivas tecnocrática e burocrática; expressões de empoderamento ativo de comunidades, engajadas em ações de benefício compartilhado.

Emerge daí novos modelos de produção apropriados à conservação do valor social, que atendam às novas necessidades de relacionamento produtor-consumidor, e ao desenvolvimento sustentado: os fenômenos de inovação social (JÉGOU \& MANZINI, 2008). Estes movimentos alteram profundamente o modo de apropriação dos recursos e se transformam em verdadeiros vetores das novas formações sociais caracterizadas pela democratização dos meios de invenção e produção, e a redução da distância entre inventor e empreendedor através da cocriação, da busca de benefícios compartilhados e do empoderamento local.

No intuito de priorizar e estabelecer que tipos de serviço público podem ser alvo de reprojeto voltado às relações, MULGAN (2012) propõe a Figura 2, que fornece uma maneira de compreender esses diferentes tipos de relacionamento.

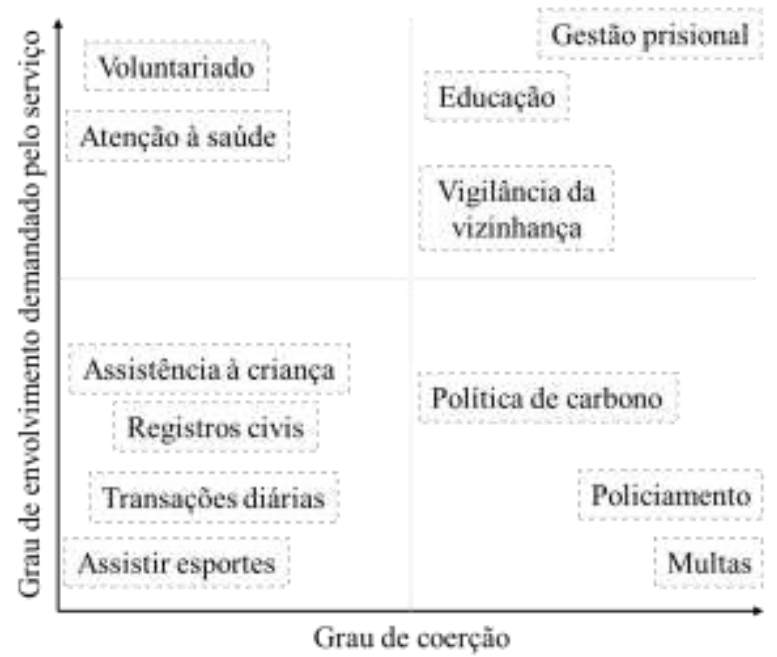

Figura 2 - Envolvimento versus coerção em serviços públicos

Fonte: Adaptado de MULGAN (2012)

MULGAN (2012) mapeia os serviços tradicionalmente providos pelo governo em duas dimensões: grau de envolvimento demandado pelo serviço, e o grau de liberdade da relação.

A dimensão referente ao envolvimento varia da vantagem em haver cidadãos envolvidos, uma que os resultados dependem de colaboração entre Estado, provedores de serviços e comunidades; até o outro extremo, onde pode ser mais adequado que as relações sejam "invisíveis". O segundo eixo, por conseguinte, busca estabelecer a gradação das assimetrias de poder e coerção contidos nas interações entre governo e cidadãos. De um lado há os serviços de alto grau de liberdade e escolhas por parte do cidadão e, de outro, o governo tem o poder de se impor. Exemplificando, o quadrante superior direito 
representa serviços que requerem envolvimento entre cidadãos e Estados, mas também altos níveis de coerção por parte deste último.

A ideia deste modelo proposto por MULGAN (2012) é orientar o projeto de serviços. Não se deve forçar envolvimento em áreas em que o mesmo pode ser inapropriado. Do mesmo modo, também chama a atenção para as áreas onde pode haver boas razões para promover mais envolvimento, onde os cidadãos querem mais envolvimento na tomada de decisões, ou quando há a necessidade de combinações de direitos e responsabilidades mais formalizada

O Estado relacional é interessado nas relações entre os cidadãos, em encorajar, apoiar e recompensar os cidadãos que se juntam para promover o bem-estar, ao contrário da visão de entrega de serviços para cidadão atomizados, passivos e consumidores. No lugar de um modelo de entrega linear, o governo se move para uma relação de mão dupla junto aos cidadãos, incentivando-os a colaborar com o governo e entre si (COTTAM, 2011).

De certa forma, a Participle iniciou um trabalho para fomentar serviços relacionais. No entanto, ainda não alcançou, na prática, os conceitos de inovações sociais sustentáveis (MANZINI, 2009). De qualquer forma, tratase de uma iniciativa válida e sustentável, que está promovendo o bem-estar por meio das relações.
Neste ambiente de mudanças relacionais, observa-se o destaque de inovadores práticos (e não de políticos), mais visível no âmbito do movimento das inovações sociais e nos locais onde a política é debatida (MULGAN, 2012). Dessa forma, CIPOLLA (2008) considera que as comunidades criativas fomentam autonomamente $\mathrm{o}$ projeto qualidades relacionais, que desafiam a disciplina do Design a propor teorias para lidar com modelos de serviço inovadores.

CIPOLLA (2008) coloca que relações interpessoais não podem ser projetadas, mas talvez estimuladas. Além disso, a autora coloca que o projeto de serviços orientados a produzir inovações sociais (ou inspirados por elas) devem "promover qualidades relacionais interpessoais entre os participantes" (CIPOLLA, 2008).

\section{Referências}

CIPOLLA, C. (2008) Creativecommunities as "relational" innovations: a service design approach. In: JÉGOU, F.; MANZINI, E.

\section{Collaborative services: Social innovationand design for sustainability.EdizioniPOLI.design}

CIPOLLA, C. (2009). Relational services and conviviality. In: MIETTINEN, S.;

KOIVISTO, N. (Eds.) Designing services with innovative methods. Otava book printing LTD. Keuruu, Finland.

CIPOLLA, C. (2012). Solutions for relationalservices. In: MIETTNEN, S. (Org). Service Design withTheory. Discussions on 
Change, Value and Methods. Rovaniemi:

Lapland University Press (LUP) Publishing.

COOKE, G.; MUIR, R. (2012) The

possibilities and politics of the re lational

state. In: INSTITUTE FOR PUBLIC

POLICY RESEARCH. The relational state:

How recognizing the importance of human

relationships could revolutionise the role

ofthestate.

COTTAM, H. (2011). Relationalwelfare.

Soundings, 48 (1), 134--- 144.

DUNLEAVY, P.; HOOD, C. (1994).

Fromoldpublicadministrationto new public management. Public Money \&

Management. Volume 14, Issue 3.

MANZINI, E. (2009) Service design in the age of networks and sustainability. In:

MIETTINEN, S., KOIVISTO, M. Designing Services with Innovative Methods. Helsinki:

Taik.

MULGAN, G. (2012). Government with the people: theoutlines of a relational state. In:

INSTITUTE FOR PUBLIC POLICY

RESEARCH. The relational state: How

recognising the importance of human

relationships could revolutionisethe role

ofthestate.

MURRAY, R.; CAULIER--- GRICE, J.; MULGAN, G. (2010) The open book of social innovation. Social innovator series: waysto design, develop and grow social innovation. The Young Foundation. 